International Journal of Engineering \& Technology, $7(4.34)(2018) 163-166$
SPC
Website: $w w w . s c i e n c e p u b c o . c o m / i n d e x . p h p / I J E T$
Research paper

\title{
Food Choice Determinants of Island Tourists: an Implication Towards Sustainable Island Tourism
}

\author{
Wan Hafiz Zainal Shukri', Fathilah Ismail ${ }^{2 *}$, Ahmad Puad Mat Som³ , N Alia Fahada W Ab Rahman² \\ ${ }^{I}$ School of Food Science and Technology, Universiti Malaysia Terengganu, 21300 Kuala Nerus, Terengganu, Malaysia \\ ${ }^{2}$ School of Maritime Business \& Management, Universiti Malaysia Terengganu, 21300 Kuala Nerus, Terengganu, Malaysia \\ ${ }^{3}$ Faculty of Applied Social Sciences, Universiti Sultan Zainal Abidin, Gong Badak Campus, 21300 Kuala Nerus, Terengganu, Malaysia \\ *Corresponding author E-mail: fathilah@umt.edu.my
}

\begin{abstract}
This study aims to investigate factors that influence food choice of international tourists at small island settings. In this study, Perhentian Island was selected as a representative of small islands as the island received the largest number of international tourists, particularly in the East Coast of Peninsular Malaysia. A close-ended questionnaire survey was conducted at various tourism spots in Perhentian Island and a total of 173 international tourists were interviewed in this study. Descriptive analysis was applied to summarize the tourists profile and travel pattern. Satisfaction gap analysis generated important factors that influence food choice among island visitors. As the majority of the international tourists to island destinations in Malaysia were on a multi-destination vacation, the results of the study could be crucial to the real needs and expectations of island tourists in Malaysia. Finally, effective development and marketing strategies could be devised to enhance the growth of food tourism, targeting remote island destinations in Malaysia.
\end{abstract}

Keywords: Island Tourism; Food Choice Determinants; Cross-Culture; Malaysia.

\section{Introduction}

Tourism research has gained interest of many researchers all over the world due to the significant contribution of tourism industry to a particular economy including Malaysia and other ASEAN countries. Tourism has emerged as a major important contributor to economic growth through the generation of foreign exchange earnings, employment and income. Tourism also stimulates the development of basic infrastructure, contributes to the growth of domestic industries, attracts foreign investment, and facilitates the transfer of technology and information. Tourism has also been regarded as a catalyst for the conservation and improvement of the environment, as well as retaining local diversity and culture. In recognition of the potential of tourism to contribute to sustainable economic growth, Malaysia has made serious efforts, particularly since the 1980s, to develop international tourism. The resilience of the tourism industry in Malaysia is attributable to the active participation of both the public and private sectors in undertaking marketing and diversifying target markets, as well as improving the competitiveness of tourism products and services. One of the emerging tourism products in Malaysia is food-based tourism. Food has always been the main concerns of tourists during their travel, and food is one example of a local cultural resource that has the potential to facilitate a number of community benefits.

\subsection{Island tourists' food consumption in Terengganu, Malaysia}

The significant implications of food consumption among tourists on destinations have received a growing interest among tourism scholars recently. Evidence from few studies suggested that tourist interest in and preferences for food in destination can play a sig- nificant role in affecting their destination choice [1-3]. Despite the importance of food consumption in the context of tourism, little is known about the phenomenon in general. According to previous research, food consumption in tourism is a unique form of eating which occurs in a foreign and unfamiliar context and has been largely been ignored in the discourse of tourism [2, 4]. What has been recently discovered from the world of literature pertaining to food consumption in tourism are: it is largely essential (tourists need to eat when they travel away from home, unless they bring their own food to the destination), it occurs in a foreign and unfamiliar context, it is of temporal nature (tourists are usually in sojourn instead of staying in the destination for a prolonged period of time), and it bears symbolic meaning and can be associated with travel motivation.

Current literature of food consumption in tourism can be distinguished into four broad areas: food as a tourist product/ attraction, tourists' food consumption behaviour/pattern [1-3], tourists' interpretation of dining experiences and previous work by [5] on tourists' special interests in various food and beverages, while [6] examined relation to destinations (e.g. food tourism, wine tourism and food events). It will provide an understanding of how international tourists perceive local food and beverage readily available at eco-tourism destinations provided by the resort operators and why they choose or not to choose the food. However, to date, few studies examine on island tourist's food consumption. The role of food in this context is a tool to provide an important linkage between tourism and small island local economy. Hence, to ensure sustainable eco-tourism industry, the knowledge obtained will provide useful insight of the need and desire of the tourists towards revising management strategies and policies regarding local food and beverage provided.

In Malaysia, studies related to the food consumption pattern, perception of the local food and food choice determinants among 
western tourists are still limited [7], more so for destinations in the East Coast Peninsular Malaysia where most exotic small island destinations are located. With increasing competition among industry players and higher food and beverage expectations posed by international tourists [8], it is imperative to know what these tourists perceived regarding local food and beverage available at island destinations and salient factors that influence tourist food choice when travelling to remote island destinations in Malaysia. Therefore, this study aims to:

- Identify demographic profile of island tourists

- Identify tourist travel pattern to island destination

- Analyze food choice determinants of island tourists

The primary aim of this study is to investigate determinants of food choice among international tourists at island destination Therefore, Perhentian Island has been chosen as case study due to the following reasons:

i) Perhentian Island is one of the most popular island destinations in Malaysia and attracts international tourists from diverse cultural and background

ii) Tourism is the major economic activity for the people living on Perhentian Island. Therefore, a sustainability issue is important for this island as the industry directly affects host communities' current life, as well as their long term welfare.

Prior to the onset of tourism, the main economic activity for the local population was fishing. However, the white sandy beaches, crystalline waters, pristine coral reefs, small sharks and variety of coral fish have caused Perhentian Island to grow into one of the most significant small island destinations in Malaysia [9]. After the island was declared a marine park, fishing activities were prohibited, reducing the fishing industry to almost nothing. Today, most of the host community is involved in tourism.

\section{Methodology}

A self-administered, close-ended questionnaire was used to survey a sample of tourists visiting Perhentian Island. The study focuses on three major aspects: visitors' profile, tourists' travel pattern, expectation and satisfaction gap. Altogether 37 attributes were chosen and they constitute important factors that influence visitors in selecting food at island destination. Both variables measuring expectation and perception were measured on 6-point scale, ranging from totally unimportant to totally important (for expectation) while for the perceptions, ranging from strongly disagree to strongly agree. The survey instrument was generally based on the previous study by $[10,7]$. The questionnaires were personally administered to all respondents at various tourism spots around Perhentian Island. A total of 173 western tourists were sampled. A descriptive analysis was used to establish tourists' profile and travel pattern. Gap analysis was adopted to measure differences between what tourists expect and what tourists actually received. Gap analysis is given by the following equation:

\section{Gap analysis $=$ Perception mean-Expectation mean}

A non-parametric method was used in this study since the data involved is an ordinal data. The Wilcoxon Signed-rank test was adopted to examine the significant differences between expectation and perception.

\section{Discussion}

The following section will discuss on three key areas: tourist demographic profiles, travel patterns and satisfaction gap.

\subsection{Tourists' demographic profiles and travel patterns}

As shown in Table 1, most of the international visitors were European and only $3.4 \%$ were non-European. High percentage of visitors to Perhentian Island were mainly from Sweden (17.9\%), closely followed by Germany and Netherlands (both at 16.8\%) and France $(12.1 \%)$. As for gender, slightly more than half of the visitors to the island are female, while a majority of them reported to be single $(57.8 \%)$. Since most of the outdoor activities at the island are considered to be adventurous in nature, it is not surprising that more than half of the visitors are in the young adult category with most the respondents having tertiary qualification (75.7\%). It is also interesting to observe that older visitors (50 years and above) only account for $0.5 \%$, despite this segment is often expected to travel to more distant places than others. The two larger proportions of visitors to Perhentian Island mainly comprised from the private /government sector and service sector $(42.8 \%)$.

Table 1: Tourists' Demographic Profiles ( $n=173$ )

\begin{tabular}{|c|c|}
\hline Characteristics & Percentage \\
\hline $\begin{array}{c}\text { Nationality } \\
\text { European } \\
\text { Non-European }\end{array}$ & $\begin{array}{c}96.5 \\
3.4\end{array}$ \\
\hline $\begin{array}{c}\text { Country of origin } \\
\text { Germany } \\
\text { Netherlands } \\
\text { Sweden } \\
\text { France } \\
\text { Others } \\
\end{array}$ & $\begin{array}{l}16.8 \\
16.8 \\
17.9 \\
12.1 \\
36.4 \\
\end{array}$ \\
\hline $\begin{array}{c}\text { Gender } \\
\text { Male } \\
\text { Female }\end{array}$ & $\begin{array}{l}40.5 \\
59.5\end{array}$ \\
\hline $\begin{array}{c}\text { Age } \\
19 \text { and below } \\
20-29 \text { years } \\
30-39 \text { years } \\
40-49 \text { years } \\
50 \text { and above }\end{array}$ & $\begin{array}{c}4.6 \\
69.4 \\
17.9 \\
6.9 \\
0.5 \\
\end{array}$ \\
\hline $\begin{array}{c}\text { Marital status } \\
\text { Single } \\
\text { Married } \\
\text { Others } \\
\end{array}$ & $\begin{array}{l}57.8 \\
17.3 \\
24.9 \\
\end{array}$ \\
\hline $\begin{array}{c}\text { Education level } \\
\text { Primary } \\
\text { Secondary } \\
\text { Tertiary }\end{array}$ & $\begin{array}{c}4.6 \\
19.7 \\
75.7\end{array}$ \\
\hline $\begin{array}{c}\text { Occupation } \\
\text { Professional (private/government) } \\
\text { Service sector } \\
\text { Manufacturing sector } \\
\text { Business owner } \\
\text { Finance sector } \\
\text { Tourism sector } \\
\text { Academician/ school teacher }\end{array}$ & $\begin{array}{c}21.4 \\
21.4 \\
4.6 \\
2.9 \\
3.5 \\
6.4 \\
8.1\end{array}$ \\
\hline
\end{tabular}

\subsection{Travel patterns}

As illustrated in Table 2, for most of the respondents it was their first visit to Malaysia (79.8\%) while much smaller percentage identified themselves as experienced travelers. The major reasons for travelling were mainly for leisure compared to less than $2 \%$ on official business trip. Slightly more than half of respondents chose to extend their stay at the island for more than 7 nights compared to a handful (11\%) who decided to stay 3 nights or fewer. Majority of respondents travelled with their spouse or partner $(42.8 \%)$, others accompanied by friends $(32.9 \%)$ and family (11.6\%), while a much smaller percentage of respondents $(12.7 \%)$ travelled alone. Since most of the visitors to the Perhentian Island were young adults, majority of them preferred non-packaged tour whereas matured adults preferred the all-inclusive packaged. Despite the respondents extended stay, almost $80 \%$ of these young adults chose to stay at resorts that provide either chalet or bungalow type accommodations for their comfort while others (20.8\%) chose cheaper types of accommodation. 


\begin{tabular}{|c|c|}
\hline \multicolumn{2}{|c|}{ Table 2: Tourists Travel Pattern } \\
\hline Background & Percentage \\
\hline Number of visit & 79.8 \\
First time & 20.2 \\
\hline Experienced traveler & \\
\hline Purpose of visit & 98.3 \\
Vacation/ leisure & 1.7 \\
Business and/ meetings & \\
\hline Length of stay & 11.0 \\
3 nights or fewer & 30.6 \\
4-6 nights & 58.4 \\
More than 7 nights & 12.7 \\
\hline Travel party type & 32.9 \\
Alone & 42.8 \\
Friends & 11.6 \\
Spouse/ partner & \\
Family & 2.3 \\
\hline Type of tour & 1.7 \\
All-inclusive & 95.8 \\
Partly inclusive & \\
Non-packaged & \\
\hline
\end{tabular}

\begin{tabular}{|c|c|}
\hline Type of accommodation & \\
Resort/chalet/bungalow & 79.2 \\
Lodge & 1.7 \\
Hostel & 15.6 \\
Camping & 0.6 \\
Others & 2.9 \\
\hline
\end{tabular}

Satisfaction gap between respondents' expectation and perception of food choice attributes

The findings for the 37 attributes were classified under 6 categories, 'convenient', 'variety', 'price', 'hygiene and food safety', 'sensory aspect', and 'health concern'. The satisfaction gap between what the respondent expected and perceived about all 6 categories were measured by the differences as illustrated in Table 3. Generally, four factors have been identified to have significant differences in gap satisfaction analysis namely 'convenient', 'hygiene and food safety', 'health concern' at $\mathrm{p}<0.001$ while 'sensory aspect' at $\mathrm{p}<0.05$.

\begin{tabular}{|c|c|c|c|c|c|}
\hline No. & Factors & Expectation Mean & Perception Mean & Gap & z-Test \\
\hline 1. & Convenient & 3.94 & 5.50 & 1.56 & $-6.59 * * *$ \\
\hline 2. & Variety & 4.11 & 4.12 & 0.01 & -0.36 \\
\hline 3. & Price & 4.30 & 4.28 & 0.01 & 0.00 \\
\hline 4. & Hygiene and food safety & 4.60 & 4.05 & -0.55 & $-7.23 * * *$ \\
\hline 5. & Sensory aspect & 4.72 & 4.58 & -0.14 & $-2.00 *$ \\
\hline 6. & Health concern & 4.13 & 3.86 & -0.27 & $-3.79 * * *$ \\
\hline
\end{tabular}

$* \mathrm{p}<0.05 \quad * * * \mathrm{p}<0.001$

\subsection{Hygiene and food safety}

Clean physical environment of local restaurants and eating place was found to be a key element in tourists' expectation based on its high mean value (see Table 3). Unfortunately, the lack of cleanliness at local restaurants and poor hygiene practice among the food handlers as experienced by these respondents resulted in high dissatisfaction gap. Previous studies have suggested that comfortable, cleanliness in physical environment can play a major role in effecting customer intention to visit a restaurant $[11,10]$. According to [10-11], appearance of the restaurant particularly cleanliness of the physical environment and outward appearance of restaurant seemed to be one of the key attributes in allowing customers on holiday to consume local food and beverages.

\subsection{Health concern}

Health concern was found to be a central motivational factor in developing tourist's interest in local foods and beverages. Some respondents believed by consuming fresh local produce, especially in unique island environment to be means of enhancing their health and vitality either physically, mentally or spiritually. With reference to the satisfaction gap analysis (-0.27), respondents perceived that the local foods and beverages provided by restaurant operators were not utilizing fresh local ingredients and offering high calorie foods in their menu, lacking healthier menu choices, hence did not contribute to the betterment of their health during their stay. The evidence for improvement and rejuvenation of respondent's physical and mental health, through healthier local food, is highly relevant, especially at island environment setting, since most respondents related their stay surrounded by unspoiled flora and fauna beauty combined with pristine water of Perhentian island as means of meditation and recuperating from their physical and mental stress back in their home country. People tend to avoid certain foods as they tended to worry about health, weight and unnatural ingredients. In the context of hospitality, the findings from the satisfaction gap analysis are parallel with [5] on central importance of health concern aspect. In [5] reported that $57.70 \%$ respondents $(n=459)$ responded that one of the key motivations of eating out on holiday is consumption of healthy food at a tourist destination.

\subsection{Sensory aspect}

Some respondents felt that sensory factors can greatly encourage them to be more adventurous and tasting more local foods and beverages, hence greatly affecting their food choice during vacation. In the gastronomy context, ASEAN region is ubiquitous among Western tourists to be the melting pot of unique flavor combinations and unusual food culture such as hawker food culture. ASEAN countries have their own unique way or slight modification in preserving and representing the country's identity vis-àvis local food and food ways by means of incorporating local ingredients, flavor combination and cooking methods [6, 2, 1]. Even though the satisfaction gap analysis showed that most respondents were satisfied with sensory aspect, despite the slightly low perception $(-0.14)$, it is an important indicator to hospitality and tourism players that there are much room for more improvement in terms of visual image of food well displayed and cooking performance. Sensory factor could play another motivational key in not only enhancing tourists' pleasure but by means of learning the local food culture, since most of the respondents were not only on a multi-destination vacation but $79.8 \%$ of respondents were classified as first time visitor to Malaysia. Respondents further added that by travelling long distance they attempt to eat fresh exotic fruits and seafood, which is regarded as an inversion from daily food consumed back at their home countries.

\subsection{Convenient}

Satisfaction gap analysis in Table 3 showed that respondents to Perhentian Island were most impressed with convenient factor (1.56), the highest satisfaction value obtained compared to other attributes. This could be explained by the fact that the majority of the tourists to Perhentian Island are young travelers. This group of tourists is usually less fussy as compared to the older group and is always seeking new experience as reported by [9].

\section{Conclusion}

This study has provided a better picture of island based tourism and food choice determinants by island tourists, particularly to Perhentian Island. The establishment of tourist profile together 
with tourists' travel pattern and identification of the important factors that motivate tourists in choosing food during their stay at island destination would certainly help in devising new strategies for sustaining island tourism in Malaysia and worldwide.

The study has shown that Perhentian Island has successfully attracted international tourists but mostly from the European market. Therefore, marketing strategies should also consider other untapped markets such as from ASEAN countries. Tourist from Association of Southeast Asian Nations (ASEAN) represents the largest market of international arrivals to Malaysia (about 70\%) [9], but only a very small number of them travelled to island destinations. Efforts should be taken to encourage them to visit our islands as well as to attract and sustain the larger number of tourists from China, Japan, Middle Eastern countries and other long haul markets.

This study also indicates that the majority of European tourists to Perhentian Island are young independent travelers. They are normally more adventurous and looking forward to experience something new, not only with regards to tourism activities, as well as food consumption at their holiday destinations. As shown by the findings of this study, one of the important factors that will influence tourists' food choice is the sensory aspect. The sensory aspects are related to the uniqueness of local food and beverages and can be regarded as an attribute of rediscovery of sensory experience. Therefore, local food service operators should be more creative in preparing and presenting local food that suits Western tourists' taste. Additionally, food service operator should increase menu varieties. Traditional food such as 'keropok lekor, sata, ketupat sotong, nasi dagang 'should be highlighted in their promotion to create tourists' awareness about the uniqueness of Terengganu Islands, as well as providing opportunity for new experience to them.

The study also indicates tourists concern about food safety and hygiene. Therefore, in order to encourage higher local food consumption and increase attractiveness of local food and beverages among tourists, food service operators should seriously take this issue into consideration rather than just focusing on profit making. At the same time, serious effort is needed from Malaysian government to encourage food safety and cleanliness among local food operator by implementing rules and regulation, as well as a close monitoring with regards to that issue. In order to increase food safety and hygiene among food service operators, a number of courses should be offered to the food service operators on a continuous basis to increase their awareness about the issue.

This study has provided useful information about motives of local food consumption among island tourists, particularly at Perhentian Island. The findings of this study are also applicable to other similar ASEAN destinations. The current study thus demonstrates that in general, island tourists were satisfied with all food choice determinants. However, the importance of cleanliness in physical environment and outward appearance of restaurant, health concern and sensory aspects needs further improvement to encourage as well as sustain the tourist's interest to revisit our destination.

\section{Acknowledgement}

The authors would like to thank the Research Management, Innovation and Commercialization Centre, Universiti Sultan Zainal Abidin, Terengganu, Malaysia for providing the financial assistance to support the publication fee of this article.

\section{References}

[1] Chang, R. C., Kivela, J., \& Mak, A. H. (2010). Food preferences of Chinese tourists. Annals of Tourism Research, 37(4), 989-1011.

[2] Cohen, E., \& Avieli, N. (2004). Food in tourism: Attraction and impediment. Annals of Tourism Research, 31(4), 755-778.

[3] Hjalager, A. M., \& Richards, G. (2002). 13 Still undigested: Research issues in tourism and gastronomy. In A. M. Hjalager \& G. Richards (Eds.), Tourism and Gastronomy. London: Routledge, pp. 224.234
[4] Bell, D., \& Valentine, G. (1997). Consuming geographies: We are where we eat. Psychology Press.

[5] Sparks, B., Bowen, J., \& Klag, S. (2003). Restaurants and the tourist market. International Journal of Contemporary Hospitality Management, 15(1), 6-13.

[6] Kim, Y. G., Eves, A., \& Scarles, C. (2009). Building a model of local food consumption on trips and holidays: A grounded theory approach. International Journal of Hospitality Management, 28(3), 423-431.

[7] Jalis, M. H., Zahari, M. S., Zulkifly, M. I., \& Othman, Z. (2009). Malaysian gastronomic tourism products: Assessing the level of their acceptance among the western tourists. South Asian Journal of Tourism and Heritage, 2(1), 31-44.

[8] Ali, F. \& Amin, M. (2014). The influence of physical environment on emotions, customer satisfaction and behavioural intentions in Chinese resort hotel industry. Journal of Global Business Advancement, 7(3), 249-372.

[9] Ismail, F. (2009). The development of small island tourism in Malaysia. $\mathrm{PhD}$ thesis, Victoria University.

[10] Yüksel, A., \& Yüksel, F. (2003). Measurement of tourist satisfaction with restaurant services: A segment-based. Journal of Vacation Marketing, 9(1), 52-68.

[11] Meiselman, H. L., Johnson, J. L., Reeve, W., \& Crouch, J. E. (2000). Demonstrations of the influence of the eating environment on food acceptance. Appetite, 35(3), 231-237. 